\title{
Hepatocyte growth factor incorporated chitosan nanoparticles augment the differentiation of stem cell into hepatocytes for the recovery of liver cirrhosis in mice
}

\author{
Sivasami Pulavendran ${ }^{1}$, Chellan Rose ${ }^{1 *}$ and Asit Baran Mandal ${ }^{2}$
}

\begin{abstract}
Background: Short half-life and low levels of growth factors in the niche of injured microenvironment necessitates the exogenous and sustainable delivery of growth factors along with stem cells to augment the regeneration of injured tissues.
\end{abstract}

Methods: Here, recombinant human hepatocyte growth factor (HGF) was incorporated into chitosan nanoparticles (CNP) by ionic gelation method and studied for its morphological and physiological characteristics. Cirrhotic mice received either hematopoietic stem cells (HSC) or mesenchymal stemcells (MSC) with or without HGF incorporated chitosan nanoparticles (HGF-CNP) and saline as control. Biochemical, histological, immunostaining and gene expression assays were carried out using serum and liver tissue samples. One way analysis of variance was used for statics application

Results: Serum levels of selected liver protein and enzymes were significantly increased in the combination of MSC and HGF-CNP (MSC+HGF-CNP) treated group. Immunopositive staining for albumin (Alb) and cytokeratin 18 (CK18), and reverse transcription-polymerase chain reaction (RT-PCR) for Alb, alpha fetoprotein (AFP), CK18, cytokeratin 19 (CK19) ascertained that MSC-HGF-CNP treatment could be an effective combination to repopulate liver parenchymal cells in the liver cirrhosis. Zymogram and western blotting for matrix metalloproteinases 2 and 9 (MMP2 and MMP9) revealed that MMP2 actively involved in the fibrolysis of cirrhotic tissue. Immunostaining for alpha smooth muscle actin ( $\alpha$ SMA) and type I collagen showed decreased expression in the MSC+HGF-CNP treatment. These results indicated that HGF-CNP enhanced the differentiation of stem cells into hepatocytes and supported the reversal of fibrolysis of extracellular matrix (ECM).

Conclusion: Bone marrow stem cells were isolated, characterized and transplanted in mice model. Biodegradable biopolymeric nanoparticles were prepared with the pleotrophic protein molecule and it worked well for the differentiation of stem cells, especially mesenchymal phenotypic cells. Transplantation of bone marrow MSC in combination with HGF-CNP could be an ideal approach for the treatment of liver cirrhosis.

\section{Introduction}

Liver cirrhosis is irreversible in many cases and leads to death if proper remedies are not taken. In recent years, numerous articles have reported the regeneration of hepatocytes or hepatocyte-like cells from stem cells $[1,2]$. Regeneration of hepatocytes and improvement of

\footnotetext{
* Correspondence: chellanrose@yahoo.co.uk

'Department of Biotechnology, Central Leather Research Institute, Adyar, Chennai-600020, India

Full list of author information is available at the end of the article
}

cirrhotic condition in mice followed by transplantation of bone marrow MSC $[3,4]$ and cross lineage differentiation of HSC into hepatocytes [5-7] have been reported earlier. The reason for the transplantation of stem cells is to promote the regeneration of tissue specific cells and subsequent morphological and functional recovery of organs of all lineage cells $[8,9]$. Hence, bone marrow stem cells could be used in all ailments associated with disorders of mesodermal, ectodermal and endodermal

\section{Ciomed Central}

(c) 2011 Pulavendran et al; licensee BioMed Central Ltd. This is an Open Access article distributed under the terms of the Creative Commons Attribution License (http://creativecommons.org/licenses/by/2.0), which permits unrestricted use, distribution, and reproduction in any medium, provided the original work is properly cited. 
lineage tissues. This appears to provide exciting new opportunities for stem cell therapy.

However, number of stem cells engrafted and differentiated after transplantation limit the treatment strategies. Furthermore, ambiguity continues over the contribution of which subpopulation of bone marrow stem cells actually differentiate into hepatocytes and restore the liver functions [10]. Moreover, the mechanism by which stem cells regenerate the respective parenchymal cells, heading to repair of the organs in vivo is yet to be completely understood. Cell fusion, in which stem cells fuse with the somatic cell in the niche, had been suggested by many authors [11] and strong evidences were reported for the transdifferentiation of stem cells [12].

Investigators attempted to improve cell therapy by a number of strategies [13] and delivery of bioactive molecules for example, growth factors, cytokines and chemokines, is one among them. Tissue repair and functional recovery after the transplantation of stem cells are augmented by the delivery of bioactive molecules that induce stem cells to differentiate into specific-lineage cells. HGF has been reported to be a potent agent for acceleration of tissue regeneration following an acute insult, as well as amelioration of tissue fibrosis and dysfunction in chronic conditions [14,15]. Though secretion of HGF after liver injury is increased, long-term secretion in the adults is questionable. Subsequently, betterment of maintenance, proliferation and differentiation of stem cells with exogenous supply of growth factors by the injured liver has been reported [7].

Despite the pleotrophic effect of HGF [16], the long term effects of exogenous HGF remain questionable because of its short half-life period. As it is also rapidly clearly by the liver in vivo, exogenous HGF is extremely unstable in the blood circulation with a half-life of only 3-5 min $[17,18]$. This makes it almost impossible to sustain a constant constantly high level of exogenous HGF in the circulation, even with repeated injections of HGF at short intervals. This necessitates the findings of the efficient alternative means to effectively deliver growth stimuli to the niche where it is needed for biological actions. Nanotechnology offers solutions for the safe and conducive transportation of therapeutic proteins to the target site [19]. Chitosan, one among the biodegradable and less antigenic natural polymers, was reported to have the potential to carry and deliver the biologically active macromolecules $[20,21]$. Hence, chitosan, in the form of nanoparticles, can be used to deliver HGF with less systemic dilution. Earlier our group has proven that HGF could be released from CNP and thus released HGF stimulated differentiation of MSC into hepatocytelike cells in vitro [22]. Here, we demonstrated, for the first time, the ability of rhHGF incorporated CNP to differentiate MSC into hepatocytes in vivo followed by the decrease of severity of cirrhotic condition.

\section{Materials and methods Animal experiments}

Six week old Balbc mice were purchased from Tamil Nadu Animal and Veterinary University, Chennai, India. Animal maintenance and handling was carried out as per the guidelines of Institutional Animal Ethics Committee. To induce liver cirrhosis, $1.0 \mathrm{ml} / \mathrm{kg}$ body weight of carbon tetrachloride $(\mathrm{CCl} 4)$ mixed with olive oil $(1: 1$ ratio) was injected intraperitonealy into female mice twice a week up to four weeks. Site of injection was changed on every dose to avoid necrosis of local skin and to obtain invariable results. Isolation of stem cells: MSC and HSC were isolated and characterized as per protocol [23]. Isolated cells showed typical mesenchymal and hematopoietic stem cell phenotypic characteristics. Treatment protocol: One day after the eighth injection of CCl4, MSC or sorted HSC with or without HGF$\mathrm{CNP}$ or saline as a control were injected into tail vein of female mice. Either MSC or HSC of $1 \times 10^{6}$ cells was taken for injection. The amount of HGF-CNP taken for injection was adjusted such that each mouse received $100 \mathrm{ng}$ of HGF. CCl4 was injected for another two weeks after cell transplantation to maintain persistent liver damage and six mice were sacrificed at predetermined time interval after post-transplantation. Liver tissue was collected after perfusing with $4 \%$ paraformaldehyde solution and preserved in formalin buffer solution for histopathological studies. For protein and total RNA isolation, liver tissue was snap-frozen in liquid nitrogen and then stored at $-80^{\circ} \mathrm{C}$.

\section{HGF incorporated nanoparticle preparation and characterization}

CNP were prepared according to the protocol of Pan et. al [24]. Briefly, $0.2 \%$ chitosan (Sigma Aldrich, USA) solution was prepared in $1 \%$ glacial acetic acid (Sigma Aldrich, USA). Nanoparticles were prepared by dropwise addition of $0.1 \%$ tripolyphosphate (TPP) (Sigma Aldrich, USA) solution into chitosan solution with or without HGF (R\&D systems, USA). Turbidity was taken as an indicator for the formation of nanoparticles and the solution was subjected to centrifugation at 20,000 rpm for $20 \mathrm{~min}$. The supernatant was discarded in the control and saved in the case of HGF added to quantify the amount of HGF in the supernatant by ELISA, using Human HGF Quantikine ELISA kit (R\&D systems, USA) as per manufactures' instructions. All measurements were carried out in triplicate. Particle size and the morphological characteristics of the nanoparticles were examined using a high resolution transmission electron microscope (HRTEM, JEM 3010, JEOL USA, 
SAIF facility, IIT-Madras). Briefly, one drop of the solution containing nanoparticles was syringe placed on a carbon film (300 mesh copper grid) allowing sitting until air-dried. The sample was stained with $1 \%$ muranyl acetate solution for $5 \mathrm{sec}$ at $7^{\circ} \mathrm{C}$ before viewing on the HRTEM.

\section{Evaluation of HGF encapsulation and release}

HGF-CNP prepared was taken into PBS of physiological $\mathrm{pH}$ and kept in reciprocal shaking water bath at $37^{\circ} \mathrm{C}$ and $35 \mathrm{rpm}$. At predetermined time intervals, the samples were subjected to centrifugation at $20000 \mathrm{rpm}$ for $20 \mathrm{~min}$ at $4{ }^{\circ} \mathrm{C}$ and the supernatant was replaced by fresh PBS. The amount of HGF released was quantified by ELIZA. All measurements were carried out in triplicate. The growth factor-loading efficiency of nanoparticles and their entrapment efficiency were calculated from the following equations:

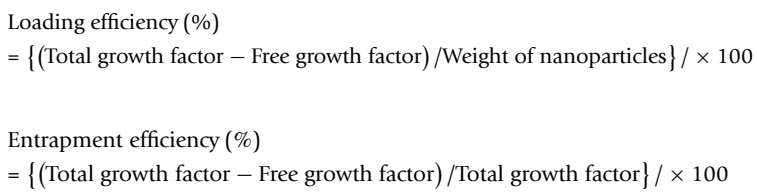

\section{Biochemical parameters}

Serum was collected to analyze alanine aminotransferase (ALT), aspartate aminotransferase (AST), and Alb. Assays were carried out at Lister Metropolis Laboratory, Chennai, India using standard automated instrumentation.

\section{Hydroxyproline assay}

To estimate hydroxyproline content, freeze-dried liver samples were hydrolyzed in $6 \mathrm{~N} \mathrm{HCl}$ in sealed tubes at $110^{\circ} \mathrm{C}$ for $18-24 \mathrm{~h}$. The hydrolyzed samples were dried over water bath and dissolved in water and then made up to a known volume. The clear supernatant obtained was used for the estimation of hydroxyproline content. The assay of hydroxyproline content was performed according to the method of Neuman and Logan [25] and the amount was expressed in $\mu \mathrm{g} / \mathrm{g}$ wet liver tissue.

\section{Zymography assay}

The liver protein sample $(50 \mu \mathrm{g})$ was electrophorezed in $10 \%$ polyacrylamide gel containing $0.1 \%$ porcine skin gelatin without reducing agent. After separation, SDS was removed from the gel by two washes each 15 minutes with $1.5 \%$ Triton $\mathrm{X}-100$. Subsequently, the gel was equilibrated using developing buffer (50 mM Tris [pH 7.4], 200 $\mathrm{mM} \mathrm{NaCl}, 10 \mathrm{mM} \mathrm{CaCl} 2,0.02 \% \mathrm{NaN} 3,1 \mu \mathrm{M} \mathrm{ZnCl} 2$ ) for 30 minutes, and incubated in the fresh developing buffer for $18-20 \mathrm{hr}$. The gel was stained with $0.25 \%$ coomasine brilliant blue (CBB) R-250 followed by destaining.

\section{Western blotting for MMP2 and MMP9 expression}

The samples $(50 \mu \mathrm{g})$ were resolved by $10 \%$ SDS PAGE and protein was transferred to PVDF membrane (Amersham, USA). After blocking with 5\% nonfat milk, the membrane was probed with anti-mouse MMP-2 (mAB, Calbiochem, Germany). After vigorous washing with TBS, the membrane was incubated with HRP-conjugated secondary antibody (Santacruz Biotechnology, USA). Western blot was developed using diaminobenzidine substrate (Sigma Aldrich, USA) and for MMP9 detection, the membrane was probed against goat antimouse MMP9 (pAB, Sigma Aldrich, USA), followed by anti-goat secondary antibody for $1 \mathrm{hr}$ and then, the color was developed using BCIP/NBT liquid substrate system (Sigma Aldrich, USA). The blot was photographed and semi-quantitative estimation was carried out.

\section{Sirius red and H\&E staining}

Paraffin fixed liver tissue was sectioned $5 \mu \mathrm{m}$ size and then, the sections of liver tissue $(5 \mu \mathrm{m})$ were stained with hematoxylin and eosin dyes for histological study. For sirius red staining, paraffin sections of $5 \mu \mathrm{m}$ thickness were dewaxed and rehydrated and then, were stained with $0.1 \%$ sirius red (Direct Red, Sigma Aldrich, USA) in saturated solution of picric acid. Staining was photographed by light microscope (Nikon, Japan).

\section{Immunofluorescence assay}

For immunofluorescence assay, paraffin fixed liver tissue was sectioned into $5 \mu \mathrm{m}$ size and then, the sections were deparaffinised and hydrated. After quenching endogenous peroxidase activity with $0.3 \% \mathrm{H} 2 \mathrm{O} 2$ in methanol, blocking was carried out using bovine serum albumin (Sigma Aldrich, USA). The blocked sections were incubated overnight at $4{ }^{\circ} \mathrm{C}$ against mouse $\mathrm{Alb}$ (pAB, abcam, USA), CK 18 and Type I collagen (mAB, Santacruz Biotechnology, USA) and $\alpha$-SMA (mAB, Sigma Aldrich, USA) antibodies. The sections were incubated with FITC conjugated secondary antibodies for 15 minutes and then the slides were viewed under fluorescence microscope (Hund Wetslar, Germany). In between steps, slides were washed with PBS.

\section{Reverse transcription PCR analysis}

Total RNA was isolated from snap frozen liver tissue using Trizol reagent (Sigma Aldrich, USA) and the ratio of absorbance values at 260 and $280 \mathrm{~nm}$ indicated an estimate of RNA purity. RT-PCR was performed using one-step RT-PCR kit (Qiagen K.K., Tokyo, Japan) with the following primers: CK18 S: A: 5'-TGGTACTC TCCTCAA TCTGCTG-3', A:5'-CTCTGGATTGACT GTGGAAGTG-3' (148 bp), CK19 S:5'-CATGGTTCT TCTTCAGGTAGGC-3', A S:5'-GCTGCAGATGAC 
TTCAGAACC-3' (291 bp), Alb S:5'-TCAACGTCAGAGCAGAGAAGC-3', A: 5'-AGACTGCCTTGTGTGGAAGACT-3', (145), AFP S: 5'-GTGAAACAGACTT CCTGGTCCT -3', A: 5'-GCC CACAGACCATGAAACAAG-3'(bp148). RT-PCR was used to evaluate chimerism in mouse liver tissue after sex mismatched stem cell transplantation. Male derived MSC and HSC were transplanted into female mice. Primers for sry gene specific for mouse testis were selected from the previous study. Forward and reverse primers were as follows: F5'AGAGATCAGCAAGCAGCTGG 3', R5' TCTTGCCTGTA TGTGATGGC 3' (bp248).PCR reactions were performed according to manufacturer's instruction with each cycle in a Eppendorf Thermal Cycler (Takara, Tokyo, Japan) using appropriate cycle profile. After the reaction, aliquots of the product were run on $1 \%$ agarose gel, stained with ethidium bromide. The amount of amplified product was quantified for each sample using a computing densitometer (Gel Doc EQ Gel documentation System; Biorad Laboratories, Hercules, CA) and software (Quantity One). The final amount of PCR product was expressed as the ratio of the respective gene amplified to that of the $\beta$ actin gene, to account for any differences in beginning amounts of RNA.

\section{Data Analysis}

Experimental results were expressed as mean \pm S.D. Analysis of variance was performed by one way analysis of variance procedures (SSPS 9.0 for Windows). Significant differences between means were determined by Dunnett's post hoc test.P $<0.05$ implies statistical significances. For histopathological assays, the sections were taken from multiple samples at various locations. The best out of these figures is given for representation in each group.

\section{Results}

\section{Physicochemical characteristics of HGF incorporated nanoparticles}

Morphological characteristics of CNP and the release pattern of HGF from CNP were studied. The loading efficiency of nanoparticles and entrapment efficiencies of HGF were $5 \mathrm{ng} \mathrm{HGF/mg} \mathrm{of} \mathrm{nanoparticles} \mathrm{and} \mathrm{85 \%}$ respectively. This was achieved with chitosan to TPP ratio at 2:1. At lower ratio, more protein could be incorporated since more positive charge from chitosan will be available. Care was taken not to form crystal-like particles during the preparation. Plain and HGF loaded nanoparticles observed by HRTEM (Figure $1 \mathrm{~A}$ and 1B) appeared spherical in shape with a particle size range of $50-100 \mathrm{~nm}$. The in vitro release profile of HGF from the nanoparticles in PBS at the predetermined time was expressed as percentage of HGF released with respect to the total amount of HGF encapsulated (Figure 1C).
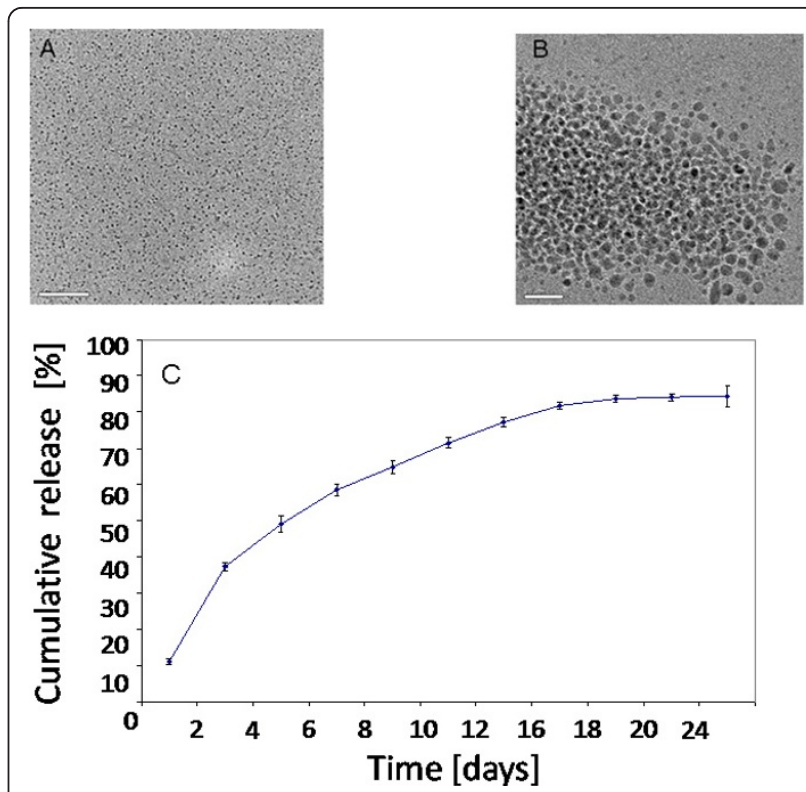

Figure 1 Chracterization of nanoparticles: High resolution TEM of (A) chitosan nanoparticles (B) HGF incorporated nanoparticles. Particles are flat and round shape (C). Cumulative release pattern of HGF from CNP. Sustainable release of growth factor could be seen from the release curve. Values are presented as mean \pm S.D for triplicate experiment

HGF release observed after 24 and 35 days was 82 and $85 \%$ respectively, indicating the monophasic release pattern of nanoparticles over a period of at least 25 days. This indicates that physical adsorption of the growth factor on the nanoparticles is unlikely, which is an essential characteristic feature for the nanoparticles required for sustained release.

\section{MSC-HGF-CNP improved liver morphology, function and hepatocytes proliferation}

The liver samples of control and HSC treated groups appeared pale and shrunken and the samples treated with MSC/+HGF-CNP were reddish brown and normal (data not shown). The liver function tests of each group after fourth week of transplantation was assessed by analyzing the serum levels of Alb, ALT and AST and the results are presented in Table 1. Elevated levels of Alb and aminotransferase enzymes were found in control, HSC and HSC+HGF-CNP treated groups. Significant increase of Alb $(2.5 \pm 0.03 \mathrm{~d}, \mathrm{dP}<0.001)$ and decreased levels of ALT $(95 \pm 5 \mathrm{~d}, \mathrm{dP}<0.001)$ and AST $(510 \pm 15 \mathrm{c}, \mathrm{cP}<0.05)$ were found in the MSC/+HGF$\mathrm{CNP}$ treated group. These findings indicated that MSC/ + HGF-CNP treatment induced the secretion of these liver specific proteins.

To verify hepatic differentiation of transplanted stem cells and subsequent recovery of liver cirrhosis, the expression of liver markers such as Alb and CK18 was 
examined in control and treated groups by immunostaining. Alb and CK18 proteins increasingly expressed in the $\mathrm{MSC} /+\mathrm{HGF}-\mathrm{CNP}$ treated group compared to other groups (Figure 2A and $2 \mathrm{~B}$ ) despite continuous injection of $\mathrm{CCl} 4$ after post-transplantation. On the other hand, the expression of these markers was less in the control and HSC/+ HGF-CNP treated groups. This observation is in good correlation with the results of biochemical parameters. The results of both biochemical and immunohistochemical studies were further confirmed by the expression of mRNAs of Alb, CK18, AFP and CK19 proteins (Figure 3A). In semiquantitative analysis of gene expression, all of these genes expressed significantly $(\mathrm{P}<0.05)$. HSC, even in the presence of HGF$\mathrm{CNP}$, did not show significant increase in the expression of these proteins and their levels were observed to be less than in MSC treated groups. Analysis of chimerism after cell transplantation is important for assessing the graft by the presence of donor cells. It is usually detected by the expression of specific gene by donor cells. Sry gene from donor male cells was detected by RT-PCR. Sry gene was expressed in all treatment groups; however, the control group did not show sry gene expression (Figure 3C).

In control and HSC treated groups, these genes were not expressed significantly. From this, it was confirmed that the transplanted MSC were able to differentiate into liver parenchymal cells, wherein HGF-CNP enhanced the process of differentiation. Wang et al (2003) showed that hepatic differentiation of HSC could be enhanced by intravenous injection of soluble HGF. None of the earlier reports explained the receptor mechanism or pathways with which HGF facilitates the differentiation of HSC after transplantation. Sry gene expressed in all transplantation experiments except control (Figure 3C). RT-PCR result for engraftment shows that chimerism in HSC treated mice is possible but the exact place where the transplanted cells is oriented is still questionable and whether undifferentiated HSC or differentiated parenchymal cell or differentiated nonparenchymal cell contribute for the chimerism is also to be understood.

\section{Histology and collagen content}

Fibrotic conditions were assessed after fourth week of transplantation using sirius red staining and hyproxyproline content of the cirrhotic tissue. The representative images for fibrosis are shown in Figure 4A. Distribution of fibrosis was extensively reduced in MSC/ $+\mathrm{HGF}-\mathrm{CNP}$ group followed by MSC alone compared to control, HSC or HSC+HGF-CNP treated groups. Quantification of fibrosis by image analysis (Figure 4B) clearly indicated that the level of fibrosis has been significantly reduced in MSC, $4.56 \pm 0.29(\mathrm{P}<0.05)$ and MSC+HGF$\mathrm{CNP}, 2.15 \pm 0.14(\mathrm{P}<0.01)$ treated groups but not in $\operatorname{HSC}(6.89 \pm 0.24)$ or HSC+HGF-CNP $(5.89 \pm 0.18)$ groups compared to control. The hyproxyproline content (Figure 4C) in HSC or HSC+HGF-CNP treated groups did not show significant difference from the control group; however in the case of MSC or MSC+HGF-

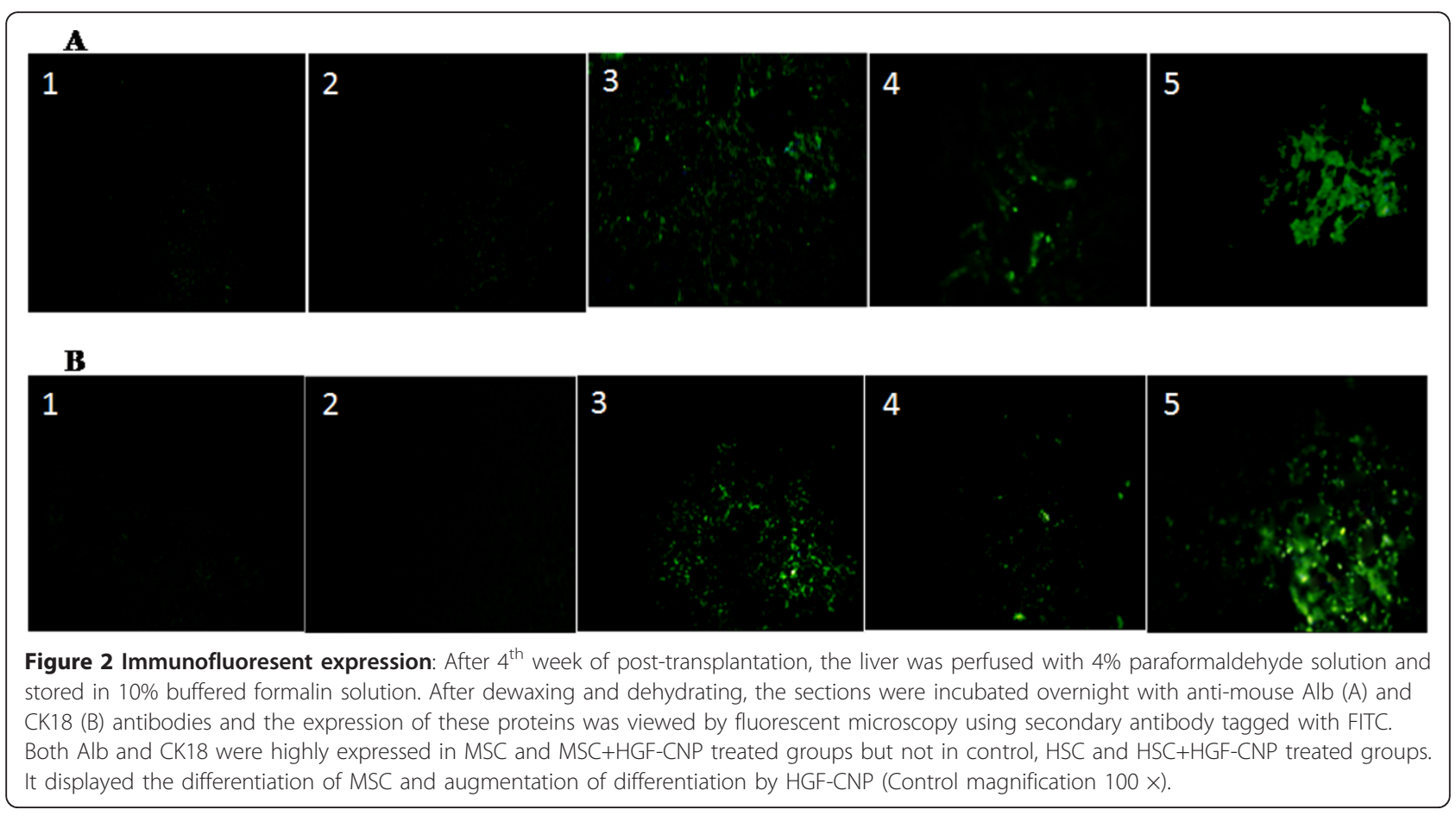




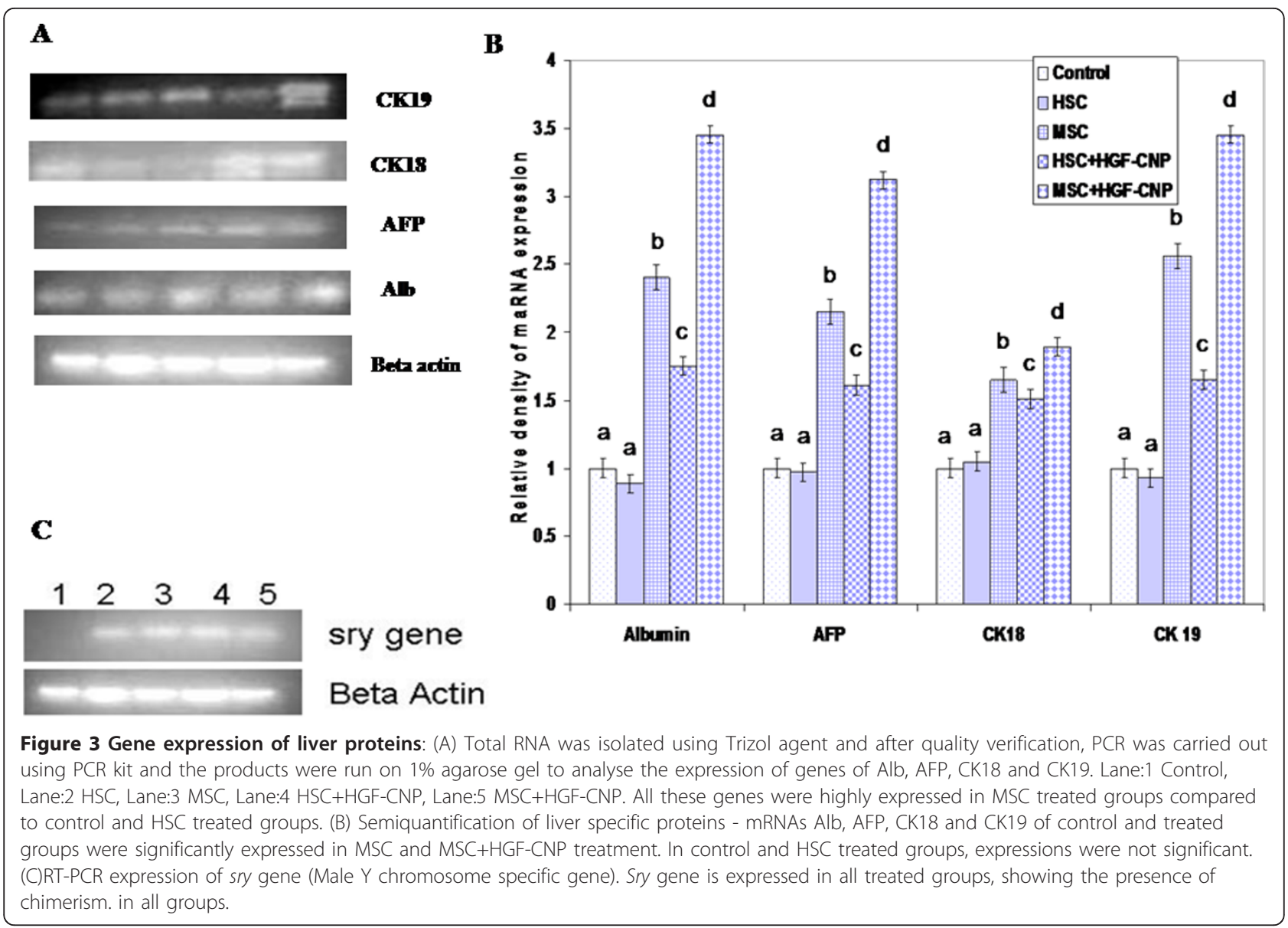

CNP treated groups, the hyproxyproline content was significantly low compared to the control $(\mathrm{P}<0.01)$. These results provided direct evidence for an antifibrotic effect of MSC and MSC + HGF-CNP combination. Figure 4D shows the histology of liver tissue of control and treated groups. The microscopical view of the H\&E stained specimens revealed the appearance of disrupted tissue architecture with large fibrous septa and infiltration of inflammatory and necrotic cells in the liver sections of control, HSC or HSC+HGF-CNP treated groups but not in MSC and MSC+HGF-CNP treated groups.

\section{MSC suppress the activation of hepatic stellate cells} Inflammatory cascade activates the quiescent hepatic stellate cells into myofibroblasts which was confirmed by the immunostaining of $\alpha$-SMA (an indicator of activated myofibroblasts). Secretion of type I collagen by myofibroblasts that leads to fibrosis was analyzed by immunofluorescence. The results of imunofluorescence study for distribution of $\alpha$-SMA positive cells around the sinusoid portion (Figure 5A) confirmed the histological observation (Figure 4D) in respect of the presence of large number of nonparenchymal cells with consistant morphology of activated myofibroblast-like cells clustered around the fibrotic septae at the end of fourth week in control, HSC or HSC+HGF-CNP treated groups. Increased expression of $\alpha$-SMA in the periportal region of liver of control, or HSC+HGF-CNP treated groups and the reduced expression of this protein in MSC and MSC+HGF-CNP groups were also noticed. Decreased expression of type I collagen, due to reduced myofibroblast activity, in MSC or MSC+HGF-CNP compared to control and other treated groups is shown in Figure 5B.

\section{MMPs activity and expression}

The fibrolytic activity of MMPs and their expression are depicted in Figure 6A and 6B respectively. The zymography assay revealed a band of gelatin degradation at $68 \mathrm{kDa}$, representing active MMP-2 and another band at $97 \mathrm{kDA}$ representing MMP9 (Figure 6A). The MSC groups, particularly MSC+HGF-CNP, showed increased expression of MMPs, more especially MMP2. The overall data on the quantitative analysis of MMP9 (Figure 6C) and MMP2 (Figure 6D) indicated that MMP9 was relatively less expressed and active compared to MMP2. 


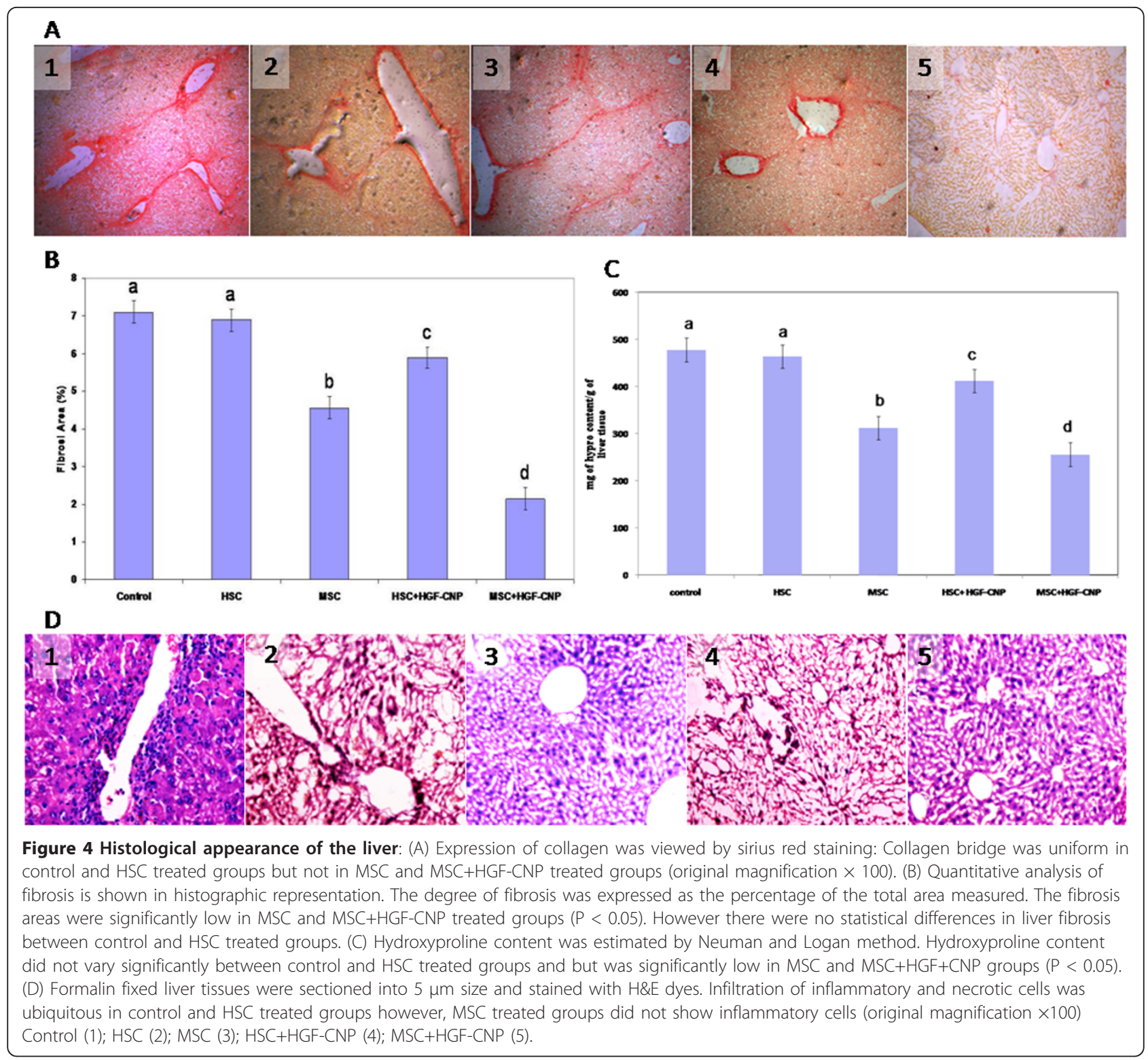

\section{Discussion}

The present study described the effect of HGF-CNP on the in vivo hepatic differentiation of stem cells. Earlier, increased expression of Alb was reported after exogenous injection of rhHGF in mice [7]; however, in vivo availability of HGF was not considered in the study since its half-life period is very short $[17,18]$. To maintain adequate level of serum HGF and overwhelming its short half-life period, repeated injection of HGF [26] and/or its gene [27] was suggested. In this study, we have incorporated HGF into CNP by ionic gelation method. Such particles can carry the therapeutic proteins to the targeted site without degradation and can sustain in the circulatory system. The protonated amino groups of chitosan as well as HGF in the acidic medium electrostatically combined with anions of TPP to form cross-linkage and this procedure ensured the systemic incorporation of growth factor into the nanoparticles instead of adsorption. Nanoparticles having the size range of 50-200 $\mathrm{nm}$ could be used effectively for the biological application by injecting them intravenously because they are capable of reaching multiorgans for therapeutic application [28]. CNP with 50-200 nm size prepared in this study (Figure 1) showed sustainable in vitro release up to 24 days as against the earlier report where the release was observed only for 8 days [29]. The cumulative release of $82 \%$ of HGF after 24 days observed in our study indicated an extended time course for sustainable release ruling out the possibility of either biphasic or burst release. This level of controlled release 


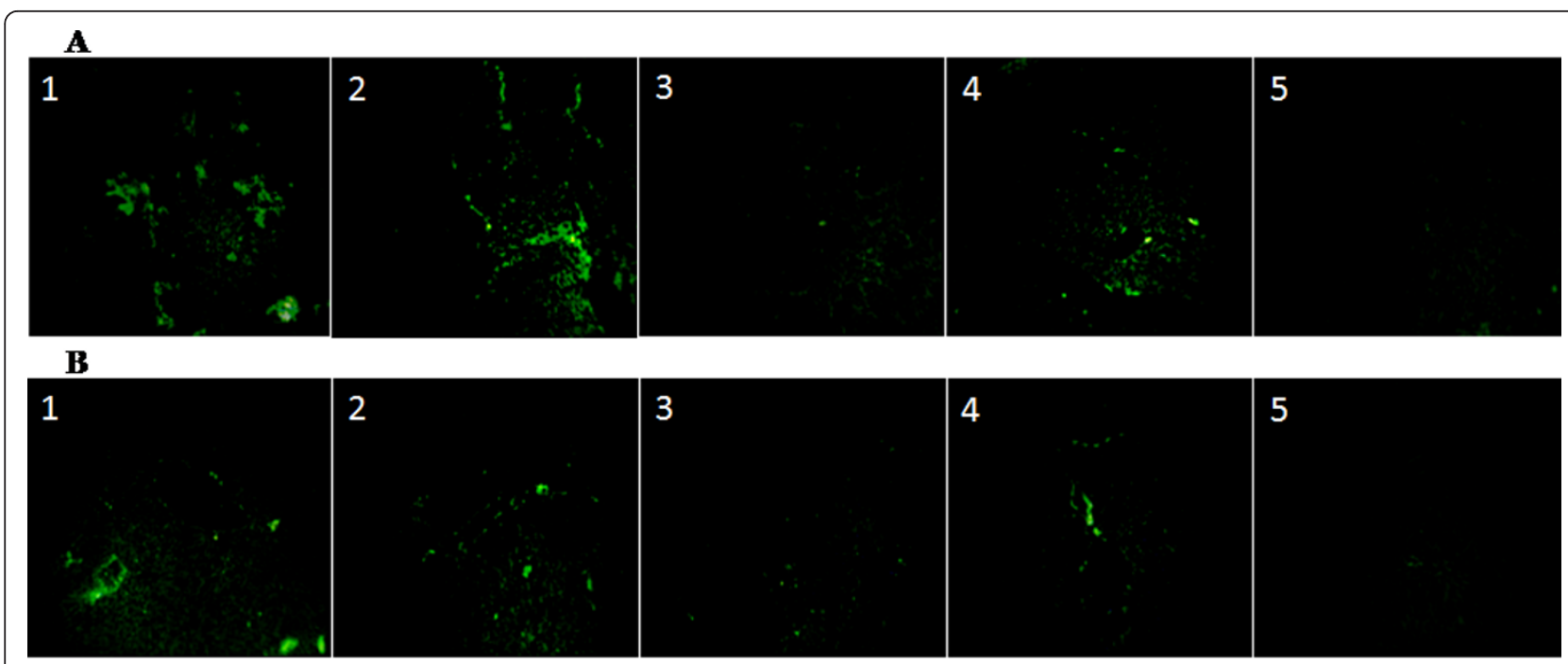

Figure 5 Immunofluoresent expression of ECM proteins: After 4th week, livers were harvested after perfusing with $4 \%$ paraformaldehyde solution and stored in 10\% buffered formalin solution. For immunofluoresence assay, the specimens after dewaxing and dehydrating were blocked for nonspecific protein using BSA. Then, the sections were incubated overnight with anti-mouse $\alpha$-SMA antibody (A): Control (A1), HSC (A2), MSC (A3), HSC+HGF-CNP (A4) and MSC+HGF-CNP (A5); and anti-mouse type I collagen antibody (B): Control (B1), HSC (B2), MSC (B3), HSC + HGF-CNP (B4) and MSC+HGF-CNP (B5). The expression of these proteins was viewed by fluorescent microscopy using secondary antibody tagged with FITC. Both $\alpha$-SMA and type I collagen expressed high in control, HSC and HSC+HGF-CNP treated groups than MSC and MSC-HGFCNP treated groups. MSC treatment suppressed the myofibroblasts and consequently made type I collagen disappeared (original magnification $\times 100)$.

(4 ng per day) could be sufficient enough to induce differentiation of stem cell as has been observed by Hasuike et al. [30]. Another important feature of this study was the effective use of HGF to a level of, as low as, $1.2 \mu \mathrm{g} \mathrm{HGF/mg} \mathrm{CNP/kg} \mathrm{body} \mathrm{weight,} \mathrm{against} 250$ $\mu \mathrm{g} / \mathrm{Kg}$ body weight [31] and $300 \mu \mathrm{g} / \mathrm{Kg}$ body weight [26] reported earlier.

Less engraftment of transplanted cells necessitated the findings of effective strategies which can differentiate and expand the transplanted cells. The process of migration of MSC to the target site was reported to be guided and accelerated in the presence of HGF [32]. the histological findings of our present study suggests that the exogenous HGF prevent the hepatocytes from necrosis and accelerated regeneration [27] as was observed in our histological results. Results of these previous studies brought forth the idea of delivery of HGF through carriers, especially nano-carrier, to aid the targeted as well as sustainable delivery. In this study we report that HGF released from HGF-CNP could also accelerate the migration of MSC to injured liver and also facilitated its hepatic differentiation, as only these cells have c-met receptor for HGF. This was supported from the results of increased expression of liver specific proteins and their genes (Figure 2 and 3). From these results, it was confirmed that the transplanted MSC were able to differentiate into liver parenchymal cells, wherein HGFCNP helped to enhance the differentiation. Wang et al.
[7] showed that hepatic differentiation of HSC could be enhanced by intravenous injection of soluble HGF. None of the earlier reports explained the receptor mechanism or pathways with which HGF facilitates the differentiation of HGF after transplantation.

Differentiation of homed stem cells at the target site was monitored by the expression of sry gene after transplantation of stem cells in sex mismatched mice. The expression of sry gene confirmed the engraftment of both HSC and MSC in the recipient's liver. RT-PCR result for engraftment showed that chimerism in HSC treated mice is possible but the exact place where the transplanted cells is oriented is still questionable and which undifferentiated HSC or differentiated parenchymal cells or differentiated nonparenchymal cell contributed for the chimerism is also to be understood. Higher expression of sry gene observed in the MSC+HGF-CNP treated group ascertained the migration followed by engraftment for the effective repopulation of tissue-specific hepatocytes. The HGF-incorporated chitosan nanoparticles can presumably work for the differentiation process in two ways: injected HGF-incorporated nanoparticles may release the growth factor in the circulation during the controlled enzymatic degradation of biopolymers and thus released HGF may enhance the differentiation; secondly, the liver being the homing organ for any foreign particles, the CNP upon reaching the liver is degraded to release the growth factor which can induce the differentiation. 


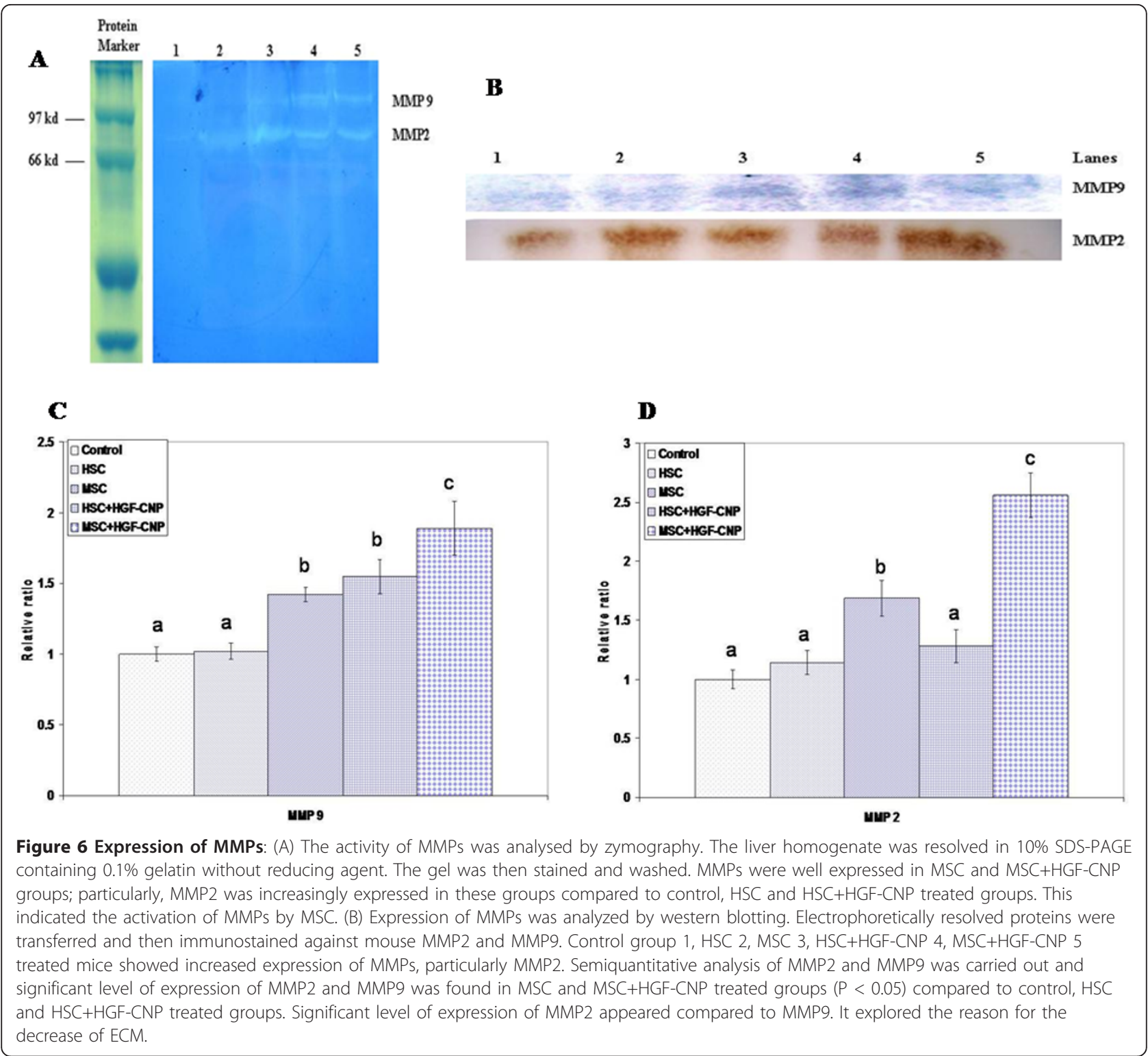

Amelioration of fibrosis and its grounds must be suppressed or stopped to prevent progression of fibrosis. Hepatic injury activates the secretion of cytokines of inflammatory cascade from the multiple inflammatory as well as parenchymal cells, which involve the healing process. Suppression of inflammatory cytokines could reduce the activation of hepatic stellate cells. Inhibition of the proliferation of $\mathrm{T}$ cells thereby modulating the pro-inflammatory cytokines such as TNF- $\alpha$ and IL1 $\beta$ by MSC was reported [33-35]. Less invasions of inflammatory cells in the MSC and MSC-+HGF-CNP treated groups connect with the anti-inflammatory action of MSC. Moreover, the direct involvement of MSC in immunomodulation of hepatic stellate cells has also been explored recently [36]. Lower level of $\alpha$-SMA positive cells in MSC treated group (Figure 5) is attributed to the anti-inflammatory activity of MSC that secrete compounds which would have reversed myofibroblasts through paracrine mechanisms.

Most of the previous studies involving the transplantation of stem cells for therapeutic purpose, concentrated on either functional recovery of liver from metabolic disease in the knockout model [37] or the fibrolysis of ECM content [38]. For better understanding we have compared the contribution of either HSC or MSC in the process of reversal of cirrhosis in the liver. A significant difference was observed in collagen content between MSC and HSC treated groups or control (Figure 4). The disappearance of collagen content in the cirrhotic liver of MSC groups was apparently due to the lysis of fibrotic tissue which was 
accomplished by MMP2 activity. MMPs more particularly the MMP2 that promote the degradation of ECM in liver cirrhosis [39] should have been secreted by MSC, which in the presence of HGF exhibited increased MMP2 activity, as observed by enhanced fibrolysis and/or prevention of collagen synthesis. This would have facilitated the assembling and orientation of stem cells in the hepatic nodules where they can differentiate into functional hepatocytes. Though HSC can differentiate and recover the liver functions to some extent, they obviously failed to degrade the ECM. The expression of MMPs by HSC either in in vitro or in vivo studies has not been reported so far. But it was reported that transplanted HSC activate T lymphocytes leading to inflammatory complications and posing health risk in hematopoietic stem cell therapy [40]. Moreover, in the cirrhotic liver, therapeutic strategies must rely on achieving repopulation of liver parenchymal cells and increased ECM degradation [41]. The potential of MSC for differentiation, immune-suppression and the secretion of matrix degradation molecules suggested that MSC based cell therapy could be used successfully for the treatment of liver inflammation and cirrhosis. This model could also be extended to the reversal of other fibrotic condition. Our further study will be extended in the direction of in vivo kinetics, distribution and stability of HGFCNP in the blood circulation. Whether HGF released from the CNP causes the stem cell differentiation or apoptosis of myofibroflasts or both of these functions must be studied in detail with the appropriate controls such as HGF, CNP and HGF-CNP alone to derive the concept to meaningful clinical applications.

\section{Conclusions}

Enhancement of regenerative effects of stem cells for the treatment of tissue injuries and genetic developmental diseases could be carried out with the multiple strategies such as gene therapy, delivery of therapeutic proteins etc. Development of biodegradable delivery devisees for the regenerative medicine is the urgent need to compensate/enhance the slow differentiation of stem cells. HGF incorporated CNP prepared in this investigation showed appreciable morphological and kinetic properties and it enhanced the differentiation of stem cells in vivo, especially mesenchymal phenotypic cells. Transplantation of bone marrow MSC in combination with HGF-CNP was seen as an ideal approach for the treatment of liver cirrhosis. This study will be extended in the direction of in vivo kinetics, distribution and stability of HGF-CNP to focus further on the localized delivery with the receptor mechanism.

\section{Acknowledgements}

The authors are thankful to the Director and the members of the Research Council of CSIR-Central Leather Research Institute for granting permission to carry out this part of the work.

\section{Author details}

'Department of Biotechnology, Central Leather Research Institute, Adyar, Chennai-600020, India. ${ }^{2}$ Chemical Laboratory, Central Leather Research Institute, Adyar, Chennai-600020, India.

\section{Authors' contributions}

SP has carried out the preparation of HGF-incorporated chitosan nanoparticle and biochemical, histological, immunostaining and gene expression assays described in the manuscript, statistical data analysis and has drafted the manuscript. CR has provided the interpretation of data of the entire manuscript and has finalized the manuscript contents with critical revisions. ABM has suggested valuable inputs with interpretation of statistical data and has duly approved the manuscript for submission to the Journal.

\section{Competing interests}

The authors declare that they have no competing interests.

Received: 30 September 2010 Accepted: 28 April 2011 Published: 28 April 2011

\section{References}

1. Dolado MA, Pardal R, Garcia-Verdugo JM, Fike JR, Lee HO, Pleffer K, Lois C, Morrison SJ, Buylla AA: Fusion of bone marrow derived cells with Purkinje neurons, cardiomyocytes and hepatocytes. Nature 2003, 425:968-973.

2. Devine SM, Cobbs C, Jennings M, Bartholomew A, Haffman R: Mesenchymal stem cells distribute to a wide range of tissues following systemic infusion into non-human primates. Blood 2003, 101:2999-3001.

3. Sato Y, Araki H, Kato J, Nakamura K, Kawano Y, Kobune M, Sato T, Miyanishi K, Takayama T, Takahashi M, Takimoto R, lyama S, Matsunaga T, Ohtani S, Matsuura A, Hamada H, Niitsu Y: Humanmesenchymal stem cells xenografted directly to rat liver are differentiated into human hepatocytes without fusion. Blood 2005, 106:756-763.

4. Pittenger MF, Mackay AM, Beck SC, Jaiswal RK, Douglas R, Moorman MA Simonetti DW, Craig S, Marshak DR: Multilineage potential of adult human mesenchymal stem cells. Science 1999, 284:143-147.

5. Lagasse E, Connors H, Al-Dhalimy M, Reitsma M, Sohse M, Osborne L, Wang X, Finegold M, Weissman IL, Grompe M: Purified hematopoietic stem cells can differentiate into hepatocytes in vivo. Nat Med 2003, 6:1229-1243.

6. Wang $X$, Willenbring $H$, Akkari $Y$, Torimaru Y, Foster M, Al-Dhalimy E, Lagasse $E$, Finegold $M$, Olson $S$, Grompe M: Cell fusion is the principal source of bone marrow derived hepatocytes. Nature 2003, 422:897-901.

7. Wang X, Ge S, Mcnamara G, Hao QL, Crooks GM, Nolta JA: Albumin expressing hepatocyte-like cells develops in the livers of immunedeficientmice transplantation with highly purified human hematopoietic stem cells. Blood 2003, 101:4201-4208.

8. Krause DS, Theise ND, Collector MI, Henegariu O, Hwang S, Gardner R: Multi-organ, multi-lineage engraftment by a single bone marrow derivedstem cells. Cell 2001, 105:369-377.

9. Afonso FA, Siapati EK, Bonnet D: In vivo contribution of murine mesenchymal stem cells into multiple cell-types under minimal damageconditions. J Cell Sci 2004, 117:5655-5657.

10. Kanazawa $Y$, Verma IM: Little evidence of bone marrowderivedhepatocytes in the replacement of injured liver. Proc Natl Acad Sci (USA) 2003, 100:11850-11853.

11. Vassilopoulos G, Wang PR, Russell DW: Transplanted bone marrow regenerates liver by cell fusion. Nature 2003, 422:901-904.

12. Yeh ET, Zhang $S$, Wu HD, Korbling M, Willerson JT, Estrov Z: Transdifferentiation of human peripheral blood CD34+enriched cell population into cardiomyocytes, endothelial cells, and smooth muscle cells in vivo. Circulation 2003, 108:2070-2073.

13. Mangi AA, Noiseux N, Kong D, He H, Rezvani M, Ingwall JS, Dzau VJ: Mesenchymal stem cells modified with Akt prevent remodeling and restore performance of infracted hearts. Nat Med 2003, 9:1195-1201.

14. Ueki T, Kaneda Y, Tsutsui H, Tsutsui H, Nakanishi K, Sawa Y, Morishita R, Matsumoto K, Nakamura K, Takahashi H, Okamoto E, Fujimoto J: Hepatocyte growth factor gene therapy of liver cirrhosis in rat. Nat Med 1999, 5:226-230.

15. Shiota G, Kunisada T, Oyama K, Udagawa A, Nomi T, Tanaka K, Tsutsumi A, Isono M, Nakamura T, Hamada H, Sakatani T, Sell S, Sato K, Ito H, Kawasaki H: In vivo transfer of hepatocyte growth factor gene accelerates 
proliferation of hepatic oval cells in a 2-acetylaminofluorenepartial hepatectomy model in rats. FEBS Lett 2000, 470:325-330.

16. Ishiki Y, Ohnishi H, Muto Y, Matsumoto K, Nakamura T: Direct evidence that hepatocyte growth factor is a hepatotrophic factor for liver regeneration and has a potent anti-hepatitis effect in vivo. Hepatol 1992, 16:1227-1235.

17. Kawaida K, Matsumoto K, Shimazu H, Nakamura T: Hepatocyte growth factor prevents acute renal failure and accelerates renal regeneration inmice. Proc Nat Acad Sci USA 1994, 91:4357-4361.

18. Ishii T, Sato M, Sudo K, Suzuki M, Nakai H, Hishida T, Niwa T, Umezu K, Yuasa S: Hepatocyte growth factor stimulates liver regeneration and elevates blood protein level in normal and partially hepatectomized rats. J Biochem 1995, 117:1105-1112.

19. Vila A, Sanchez A, Tobio M, Calvo P, Alonso MJ: Design of biodegradable particles for protein delivery. J Cont Rel 2002, 78:15-24.

20. Roy K, Mao HQ, Huang SK, Leong KW: Oral gene delivery with chitosanDNA nanoparticles generates immunologic protection in a murine model of peanut allergy. Nat Med 1999, 5:387-391.

21. Amidi $M$, Romeijn $S G$, Borchard $G$, Junginger $H E$, Hennink WE, Jiskoot W: Preparation and characterization of protein-loaded N-trimethyl chitosan nanoparticles as nasal delivery system. J Cont Rel 2006, 111:107-116.

22. Pulavendran S, Rajam M, Rose $C$, Mandal AB: Hepatocyte growth factor incorporated chitosan nanoparticles differentiate murine bone marrow mesenchymal stem cell into hepatocytes in vitro. IET Nanobiotechnol 2010, 4:51-60.

23. Pulavendran S, Vignesh J, Rose C: Differential anti-inflammatory and antifibrotic activity of transplanted mesenchymal vs. hematopoietic stem cells in carbon tetrachloride-induced liver injury in mice. Int Immunopharmacol 2010, 10:513-519.

24. Pan Y, Li Y, Zhao H, Zheng J, Xu H, Wei G, Hao JS, Cui FD: Bioadhesivepolysaccharide in protein delivery system: chitosan nanoparticles improve the intestinal absorption of insulin in vivo. Int J Pharmacol 2002, 249:139-147.

25. Neuman RE, Logan MA: The determination of collagen and elastin in tissues. J Biol Chem 1950, 186:549-556.

26. Kim W, Matsumoto K, Bessho K, Nakamura T: Growth inhibition and apoptosis in liver myofibroblasts promoted by hepatocyte growth factor leads to resolution from liver cirrhosis. Amer J Pathol 2005, 166:1017-1028.

27. Xue F, Takahara T, Yata Y, Kuwabara Y, Shinno E, Nonome E, Minemura M, Takahara S, Li X, Yamato E, Watanabe A: Hepatocyte growth factor gene therapy accelerates regeneration in cirrhotic mouse liver after hepatectomy. Gut 2003, 52:694-700

28. Jong W, Hagens W, Krystek P, Burger M, Sips A, Geertsma R: Particlesizedependent organ distribution of gold nanoparticles after intravenous administration. Biomaterials 2008, 29:912-1919.

29. Calvo P, Remunanlocpez C, Vila-jato JL, Alonso MJ: Novel hydrophilic chitosan-polyethylene oxide nanoparticles as protein carriers. J Appl PolySci 2007, 63:125-132.

30. Hasuike S, Ido A, Uto H, Moriuchi A, Tahara Y, Numata M, Nagata K, Hori T, Hayashi K, Tsubouchi H: Hepatocyte growth factor accelerates the proliferation of hepatic oval cells and possibly promotes the differentiation in a 2-acetylaminofluorene/partial hepatectomy model in rats. J Gastro Hepato 2005, 20:1753-1761.

31. Yoshikawa A, Kaido T, Seto S, Yamaoka S, Sato M, Ishii T, Imamura M: Hepatocyte growth factor promotes liver regeneration with prompt improvement of hyper-bilirubinemia in hepatectomized cholestatic rats. J Surg Res 1998, 78:54-59.

32. Duan HF, Wu CT, Wu DL, Lu Y, Liu HJ, Ha XQ, Zhang QW, Wang H, Wang LS: Treatment of myocardial ischemia with bone marrow derived mesenchymal stem cells over expressing hepatocyte growth factor. Mol Ther 2003, 8:467-474

33. Zappia E, Casazza S, Pedemonte E, Benvenuto F, Bonanni I, Gerdoni E, Giunti D, Ceravolo A, Cazzanti A, Frassoni F, Mancardi G, Uccelli A: Mesenchymal stem cells ameliorate experimental autoimmuneencephalomyelitis inducing T-cell anergy. Blood 2005, 106:1755-1761.

34. Guo J, Lin GS, Bao CY, Hu ZM, Hu MY: Anti-inflammation role for mesenchymal stem cells transplantation in myocardial infarction. Inflammation 2007, 30:97-104.

35. Blanc KL, Ringde O: Immunomodulation by mesenchymal stem cells and clinical experience. J Intern Med 2007, 262:509-525.
36. Parekkadan B, Poll D, Megeed Z, Kobayashi E, Tilles A, Berthiaume F, Yarmush M: Immunomodulation of activated hepatic stellate cells by mesenchymal stem cells. Biochem Biophys Res Commun 2007, 363:247-252.

37. Kallis YN, Alison MR, Forbes SJ: Bone marrow stem cells and liver disease. Gut 2007, 56:716-724.

38. Tsukada S, Parsons CJ, Rippe RA: Mechanisms of liver fibrosis. Clin Chim Acta 2006, 364:33-60

39. Ries C, Egea V, Karow M, Kolb H, Jochum M, Neth P: MMP-2, MT1-MMP, and TIMP-2 are essential for the invasive capacity of human mesenchymal stem cells: differential regulation by inflammatory cytokines. Blood 2007, 109:4055-4063.

40. Mattern T, Girroleit G, Flad HD, Rietschel ET, Ulmer AJ: CD34 thematopoietic stem cells exert accessory function in lipopolysaccharide-induced T cell stimulation and CD80 expression on monocytes. J Exp Med 1999, 189:693-699.

41. Munoz R, Dias DM, Suarez-Cuenca JA, Trejo-Solis C, Lopez V, Yonez L, De Sanchez VC: Adenosine reverses a pre-established CCl4-induced micronodular cirrhosis through enhancing collagenolytic activity and stimulating hepatocyte cell proliferation in rats. Hepatol 2001, 34:677-687.

doi:10.1186/1477-3155-9-15

Cite this article as: Pulavendran et al:: Hepatocyte growth factor incorporated chitosan nanoparticles augment the differentiation of stem cell into hepatocytes for the recovery of liver cirrhosis in mice. Journal of Nanobiotechnology 2011 9:15.

\section{Submit your next manuscript to BioMed Central and take full advantage of:}

- Convenient online submission

- Thorough peer review

- No space constraints or color figure charges

- Immediate publication on acceptance

- Inclusion in PubMed, CAS, Scopus and Google Scholar

- Research which is freely available for redistribution

Submit your manuscript at www.biomedcentral.com/submit
Ciomed Central 